\title{
Isolation of Quartz Grains for Optically Stimulated Luminescence (OSL) Dating of Quaternary Sediments for Paleoenvironmental Research
}

\author{
Liliana C. Marin ${ }^{1}$, Steven L. Forman ${ }^{1}$, Victoria T. Todd ${ }^{1}$, Connor Mayhack ${ }^{1}$, Ashley Gonzalez ${ }^{1}$, Peng Liang ${ }^{2}$ \\ ${ }^{1}$ Geoluminescence Dating Research Laboratory, Dept. of Geosciences, Baylor University ${ }^{2}$ School of Earth Sciences, Zhejiang University
}

\section{Corresponding Author}

Liliana C. Marin

liliana_marin@baylor.edu

\section{Citation}

Marin, L.C., Forman, S.L., Todd, V.T., Mayhack, C., Gonzalez, A.,

Liang, P. Isolation of Quartz Grains for Optically Stimulated Luminescence (OSL) Dating of Quaternary Sediments for Paleoenvironmental Research. J. Vis. Exp. (174), e62706, doi:10.3791/62706 (2021).

\section{Date Published}

August 2, 2021

DOI

$10.3791 / 62706$

URL

jove.com/video/62706

\section{Abstract}

Optically stimulated luminescence (OSL) dating quantifies the time since mineral grains were deposited and shielded from additional light or heat exposure, which effectively resets the luminescence clock. The systematics of OSL dating is based on the dosimetric properties of common minerals, like quartz and feldspar. The acquired luminescence with exposure to natural ionizing radiation after burial provides a depositional age for many Quaternary sedimentary systems, spanning the past $0.5 \mathrm{Ma}$. This contribution details the procedures for separating pure quartz grains of a known range of particle sizes to facilitate luminescence analysis with small or single grain aliquots. Specifically, protocols are given for the needed data and interpretations for effective OSL dating of terrestrial sediment cores or sample tubes from exposures. These cores, 5-20 m long in $1.2 \mathrm{~m}$ sections, are split lengthwise and crown-cut leaving $80 \%$ of core volume undisturbed, which facilitates sampling of light-protected sediment for OSL dating deep within the core. Sediment samples are then subjected to a series of physical separations to obtain a certain grain-size interval (e.g., 150-250 $\mu \mathrm{m}$ ). Magnetic minerals are removed in wet and dry states using magnets. A series of chemical digestions starts with soaking in $\mathrm{H}_{2} \mathrm{O}_{2}$ to remove organic matter, followed by $\mathrm{HCl}$ exposure to remove carbonate minerals, followed by density separation. Subsequently, grains are soaked in $\mathrm{HF}$ for 80 min and after in $\mathrm{HCl}$ to render solely quartz grains. The mineralogic purity (>99\%) of the quartz extract is quantified with grain petrographic assessment and Raman spectroscopy. Repeating this quartz isolation procedure may be necessary with sediment that contains $<15 \%$ quartz grains. Excitation of the purified quartz grains by LED-derived blue and IR light allows calculations of the fast and IR depletion ratios, which are metrics to assess the dominance of luminescence emissions from quartz. 


\section{Introduction}

Optically stimulated luminescence (OSL) geochronology yields the time from the last light or heat exposure after sediment erosion, deposition and burial; and further exposure to light or heat. Thus, natural sedimentary processes or heating events $\left(>300{ }^{\circ} \mathrm{C}\right)$ reduces the previously inherited luminescence signal to a consistently low level. In the past two decades, there have been substantial advances in luminescence dating, such as single aliquot and grain analysis of specific mineral grains, like quartz. These experiment-based dating protocols with blue or green diodes can compensate effectively for sensitivity changes induced in the laboratory, rendering OSL ages for the past ca. 500 $\mathrm{ka}^{1,2,3}$.

Silicate minerals such as quartz and potassium feldspar have varying crystal lattice-charge defects; some formed at the time of mineral crystallization and others due to subsequent exposure to ionizing radiation, resulting in geochronometric potential. These defects are probable locations of electron storage with trap-depth energies of 1.3-3 eV. A subpopulation of contained electrons in latticecharge defects of quartz grains is a source for timediagnostic luminescence emissions with excitation by blue light. Thus, this luminescence emission increases with time, above the solar or heat reset level with exposure to ionizing radiation during the burial period. This signal is reduced to a low, definable level ("zeroed") with subsequent sunlight exposure with sediment erosion, transport, and deposition. This luminescence "cycle" occurs in most depositional environments on Earth and other planets. Thus, OSL dating of sedimentary quartz grains provides a depositional age, reflecting the time elapsed since the last light exposure with deposition and burial (Figure 1).

Luminescence dating is a dosimetric-based technique that yields age estimates for selected mineral grains, like quartz, from eolian, fluvial, lacustrine, marine, and colluvial sediments associated with enumerable contexts for geomorphic, tectonic, paleontologic, paleoclimatic, and archaeologic research $2,4,5,6,7$. OSL dating is also being evaluated to constrain surface processes on other planets, particularly on Mars ${ }^{8,9}$. Often, the most used mineral in OSL dating on Earth is quartz, reflecting its natural abundance, an inherent sensitivity as a geochronometer, signal stability, and rapid resetting with sunlight exposure (seconds to minutes) $4,10,11,12$. However, the accuracy of OSL dating is compromised if the quartz extract is impure, particularly if contaminated by potassium and other feldspars, which can have luminescence emissions ten to hundred-fold brighter than quartz and can yield age underestimates ${ }^{13}$. Therefore, the absolute (>99\%) purity for extracts of quartz grains from sediment is pivotal for accurate OSL dating. Thus, the focus of this contribution is to provide detailed procedures for isolating highly purified quartz grain separates from a variety of polymineral sediments. This requires integration of knowledge of mineralogy, crystal chemistry; optical and Raman imaging, to effectively apply laboratory protocols, to render OSL ages on quartz grains from carefully sampled strata from retrieved sediment cores. The sediment cores were collected by a push and percussion coring method, which retrieved intact sediment down to a depth of 20-25 m.

The OSL time-sensitive signal is reset relatively rapidly with minutes to hours of sunlight exposure. The geological OSL 
signal accumulates from this solar reset level. Although, the OSL emissions of quartz are considerably variable, reflecting original crystalline structure, lattice impurities, sensitization with luminescence resetting cycles ${ }^{14}$ (Figure 1). Thus, there is inherent variability in the dose sensitivity of quartz, and dating protocols need to be devised for specific mineralogic and sedimentary provenance. Fortunately, the emergence of single aliquot regenerative (SAR) dose protocols for quartz $^{1,2}$ yielded systematics to redress variability in the OSL emissions and metrics to evaluate laboratory changes in apparent OSL sensitivity. Sediment grains function as longterm radiation dosimeters when concealed from further light exposure, with the luminescence signal serving as a measure of radiation exposure during the burial period. The radiation dose that is equivalent to the natural luminescence emission of isolated quartz grains is referred to as the equivalent dose ( $D_{e}$ : in grays, Gy), which is the numerator of the OSL age equation (Equation 1). The denominator is the Dose rate ( $D_{r}$ : Grays/yr.), defined by contributing $\alpha, \beta$, and $y$ radiation, originating from the radioactive decay of daughter isotopes in the ${ }^{235} \mathrm{U},{ }^{238} \mathrm{U},{ }^{232} \mathrm{Th}$ decay series, ${ }^{40} \mathrm{~K}$, and with lesser contributions from the decay of ${ }^{85} \mathrm{Rb}$ and cosmic and galactic sources.

OSL age $(\mathrm{yr})=\frac{\text { Equivalent dose }\left(\mathrm{D}_{e} ; \text { grays }\right)}{\text { Dose rate }\left(\mathrm{D}_{r} ; \text { grays } / \mathrm{yr}\right)=\mathrm{D}_{\alpha} \mathrm{w}+\mathrm{D}_{\beta} \mathrm{w}+\mathrm{D}_{\boldsymbol{\gamma}} \mathrm{w}+\mathrm{D}_{c}}$ (Equation 1)

Where, $D_{\alpha}=$ alpha dose $D_{\beta}=$ beta dose $D_{\gamma}=$ gamma dose $D_{C}=$ cosmic dose and $w=$ water attenuation factor.

Another method for $\mathrm{U}$ and Th determinations in the laboratory or the field is gamma spectrometry, with the Germanium variant able to quantify $U$ and Th isotopic disequilibrium with suitable adjustments to the dose rate. The beta and gamma components of the environmental dose rate need to be modified for mass attenuation ${ }^{15}$. However, there is an effectively insignificant alpha dose for grains $>50 \mu \mathrm{m}$ with the outer $10-20 \mu \mathrm{m}$ of grains removed by treatment with undiluted HF during preparation. A critical component in dose rate assessment is the quantification of the cosmic and galactic dose during the burial period, which is calculated for specific points on Earth with adjustments for longitude, latitude, elevation, burial depth, and density of overlying sediment ${ }^{16,17}$.

Sediments that contain $>15 \%$ quartz are usually relatively straightforward for separating out a high purity quartz fraction. However, sediments with $<15 \%$ quartz often require added time to ensure needed mineralogic purity for OSL dating. Approximately 500-1000 quartz grains are needed for this analysis, but often thousands of grains are separated for duplicate analyses, archiving to expand a calibration library, and future advancements. The mineralogic composition of sediment samples is initially assessed, grain by grain, by petrographic analysis through a binocular microscopic (10-20x) and associated imagine analysis. The mineralogy of individual grains is tested further by Raman spectroscopy to measure grain spectra using an excitation laser $(455 \mathrm{~nm}$, $532 \mathrm{~nm}, 633 \mathrm{~nm}$, or $785 \mathrm{~nm}$ ) and statistically compare grain emissions to known mineral spectra from the RRUFF System Database $^{18}$.

Once the visual and spectral inspection is satisfactory, the purity of the OSL signal is further checked, utilizing an automated luminescence reader system. Three to five aliquots of the sample are exposed to infrared excitation (IR $=1.08$ watts at $845 \mathrm{~nm} \pm 4 \mathrm{~nm})$, which preferentially stimulates feldspar minerals, and this emission is compared to emissions by blue light excitation ( $\mathrm{BI}=470 \mathrm{~nm} \pm 20 \mathrm{~nm}$ ), which preferentially stimulates quartz. If the ratio $|R / B| \geq 5 \%$, 
the test indicates feldspar contamination and acid digestions are repeated. If the ratio $|\mathrm{R} / \mathrm{B}|<5 \%$, then the samples are deemed quartz fraction satisfactorily for dating.

Single aliquot regeneration (SAR) protocols on quartz grains is an often-used approach in OSL dating sediments with procedures tailored for a specific sample, a study site, or an area. The reproducibility of these protocols is determined by giving quartz grains a known beta dose (e.g., $30 \mathrm{~Gy}$ ) and evaluating what heat pretreatment recovers this known dose (Figure 2). In practice, determining a $D_{e}$ with the SAR protocols involves the calculation of a ratio between the natural luminescence and the luminescence from a known test dose ( $\mathrm{L}_{n} / T_{n}$ ratio), which is compared to the luminescence emissions for regenerative doses divided by the luminescence from the same test dose $\left(L_{X} / T_{X}\right)$ (Figure 2). A correction, a consistently applied test-dose (e.g., $5 \mathrm{~Gy}$ ), has been devised to compensate for quartz grain(s) sensitivity changes with measurement through SAR cycles. Often the OSL emissions increase by $>5 \%$ with each successive SAR cycle, though given the same dose (e.g., $5 \mathrm{~Gy})^{7}$.

At least forty aliquots of quartz or 500 grains are analyzed with TL/OSL reader system, with blue light excitation. The luminescence data generated is analyzed by software associated with the Risø TL/OSL-DA-20 reader system. The $D_{e}$ and $D_{r}$ values and age estimates are calculated using the Luminescence Dose and Age Calculator (LDAC) ${ }^{17}$. This platform applies statistical models to determine equivalent dose $\left(D_{e}\right)$ values and render corresponding OSL age with constrained errors.

The extracted light-shielded sample from a core is prepared for two reasons: 1) To obtain a mineralogic fraction of quartz grains with a purity of $>99 \%$, and 2) To isolate grains of specific size fraction, e.g., 150-250 $\mu \mathrm{m}$, for assessment of the environmental $D_{r}$ for OSL dating ${ }^{17}$. In many sedimentary settings, quartz grains are common; but mixed with other silicate and non-silicate minerals, rock fragments, and organic matter. Previously, procedures were briefly outlined, indicating some specific steps and reagents needed to isolate pure quartz grains in the context of OSL dating $13,19,20,21,22,23$. This contribution has benefited greatly from these previous approaches. This paper outlines revised, and more detailed protocols using petrographic imaging and Raman technology to monitor grain mineralogy and render highly pure (>99\%) quartz extracts for luminescence dating. These quartz isolation protocols have been developed after preparing hundreds of samples from diverse geological environments in the Americas, Eurasia, China, and Africain, the Baylor Geoluminescence Dating Research Laboratory, reflecting analytical experience over thirty years, and are not definitive methods, with suitable variations used by other labs. These are not static protocols, and modifications and additions for improvement are welcomed.

\section{Protocol}

NOTE: This section presents the procedures to separate a nearly pure (>99\%) quartz fraction from polymineral sediments taken from long $(15-20 \mathrm{~m})$ sediment core and are equally applicable to individual tube-like samples collected from outcrops ${ }^{23}$. This methodology has been divided into three components: (1) Sediment core opening, description, and interpretation of sedimentary environments to place the resultant OSL age into a paleoenvironmental context, (2) Retrieval of a small OSL sediment sample from a core without exposure to ambient light, and (3) Separation of a monomineralogic quartz extract at a specific size fraction (e.g., $150-250 \mu \mathrm{m})$. The first step is conducted under ambient light conditions. The second and third components are undertaken 
with illumination by a sodium vapor bulb, equivalent LEDs, or bulbs with a red to orange filter. Test have shown that these safe light conditions with emissions centered on 589 $\mathrm{nm}$ with about $1-0.5 \mathrm{~W} / \mathrm{m}^{2}$ on the bench surface do not cause inadvertent reset during grain preparations.

\section{Open, describe and interpret sediment cores ( Figure 3)}

NOTE: Use an electric saw at about the quarter diameter (0.5radian position) of the circumference of the core to open them lengthwise. Perform this "crown" core cut instead of a halfcut to preserve more unlighted-exposed sediment for OSL dating and other analysis without compromising careful visual inspection, sampling, and description of the core.

1. Log and evaluate the sedimentologic and pedologic features of a core.

1. Evaluate the variation in sedimentologic features such as particle size changes, sedimentary and diagenetic structures, bedding if visible, Munsell colors $^{24}$, the basis for unit boundaries ${ }^{25}$ and identifying sequences of strata.

2. Ascertain macro-pedologic features including carbonate, argillic and cummlic morphologies; rubification and associated horizon designation; and trace fossils.

3. Take 1-2 $\mathrm{g}$ of the sediment with a spatula, put it in a $50 \mathrm{~mL}$ acid-resistant beaker to assess the carbonate content gasometrically.

1. Place the beaker in a well-ventilated box oven $\left(40{ }^{\circ} \mathrm{C}\right)$ for at least $8 \mathrm{~h}$ to dry the sample, then weigh on a precision scale and annotate the weight for each sample in the lab book.
2. Add $30 \mathrm{~mL}$ of $15 \% \mathrm{HCl}$ to the sample, place it uncovered inside a fume hood and let it react for at least $30 \mathrm{~min}$. Add acid until the reaction is complete.

CAUTION: $\mathrm{HCl}$ acid should always be used inside a fume hood, with the sash no more than a quarter open. A lab coat, chemicalresistant gloves, safety goggles, and a shield are required when handling $\mathrm{HCl}$. Place this mixture in a fume hood for $8 \mathrm{~h}$ covered by a wax paper sealant. The reaction of $\mathrm{HCl}$ with $\mathrm{Ca} /$ $\mathrm{MgCO}_{3}$ is exothermic. Thus, place the beaker in a $300 \mathrm{~mL}$ ceramic bowl filled with $100 \mathrm{~mL}$ of cold tap water to cool the reaction and capture reaction spillage.

3. Wash the sample with $100 \mathrm{~mL}$ of deionized water (DIW), carefully decant the supernatant in to sink without losing the sediment.

4. Return the sample to the oven $\left(40{ }^{\circ} \mathrm{C}\right)$ for at least $24 \mathrm{~h}$ until dry; weigh and record the value.

5. Quantify the mass difference between ovendried samples before and after soaking in 15\% $\mathrm{HCl}$ to assess carbonate content (\%).

4. Remove $0.5-1.0 \mathrm{~g}$ of sediments for particle size analysis every $5-10 \mathrm{~cm}$ down the core. Place each sediment sample in a $100 \mathrm{~mL}$ acid-resistant beaker. Label the samples in beakers accordingly.

5. Sieve the sediments through a $2000 \mu \mathrm{m}$ mesh. Discard the sediment $>2000 \mu \mathrm{m}$ (larger than sand). Continue the process with the remainder sediment $<2000 \mu \mathrm{m}$.

6. Add $30 \mathrm{~mL}$ of $15 \% \mathrm{HCl}$ to remove carbonate from the sample. Repeat steps 1.1.3.1-1.1.3.5 
7. Remove the organic matter using $30 \mathrm{~mL}$ of $12 \%$ $\mathrm{H}_{2} \mathrm{O}_{2}$ and let it stand for $>12 \mathrm{~h}$; do not heat.

CAUTION: $\mathrm{H}_{2} \mathrm{O}_{2}$ promotes rapid oxidation, is corrosive, and can be very harmful to the eyes, skin, and respiratory system. A lab coat, chemicalresistant gloves, safety goggles, and a shield are required when handling reagent-grade $\mathrm{H}_{2} \mathrm{O}_{2}$. The addition of $\mathrm{H}_{2} \mathrm{O}_{2}$ to sediment containing organic matter is an exothermic reaction. The rapid increase in temperature is proportional to the abundance of organic matter disseminated in the sample. The addition of DIW may be necessary to keep reaction temperature $<40{ }^{\circ} \mathrm{C}$. Continue to add $\mathrm{H}_{2} \mathrm{O}_{2}$ and monitor reaction temperature simultaneously. Let the mixture remain inside a fume hood for $8 \mathrm{~h}$ covered by a wax paper sealant. Place the beaker in a $300 \mathrm{~mL}$ ceramic bowl filled with $100 \mathrm{~mL}$ of cold tap water to cool the reaction and capture reaction spillage.

8. Determine grain sizes for each sample with a laser diffraction particle size analyzer and classify the range of grain sizes according to the Wentworth scale $^{26,27}$.

9. Assess the data and iteratively resample using finer spacing $(2-5 \mathrm{~cm})$ to characterize the unit contacts better or the imprint of pedogenesis (see Figure 4).

2. Interpret the sedimentary and stratigraphic sections.

1. Use the resultant logs of sedimentology, stratigraphy, pedology, granulometry, and carbonate percentage to define the depositional units and pedosedimentary facies observed in cores.
2. Draft the respective sedimentary sections for each core (Figure 4).

3. Interpret the sedimentary and environmental information based on an integrated assessment of the physical core description and granulometry, carbonate content, micromorphology, and facies analysis. Discuss the interpretation of sedimentary environments with others in the research group.

4. Determine specific depth levels of the cores to be sampled for OSL dating to decipher depositional events $^{7}$.

\section{Collect OSL sample (Figure 5)}

NOTE: The core sections are transferred to the luminescence lab to sample for OSL dating in safe light conditions.

1. Moisten the core face with DIW using a squeeze bottle to ensure sediment cohesion.

2. Define the sampling area by scoring with a spatula a 2$\mathrm{cm}$ diameter circle from the center point of the core face.

3. Scrape off the upper $1 \mathrm{~cm}$ of light exposed sediment with a utility knife. Put this sediment in a labeled ceramic evaporation dish to dry for at least $8 \mathrm{~h}$ in a box oven at $40{ }^{\circ} \mathrm{C}$. Pulverize and homogenize this dried sediment sample for $\mathrm{U}, \mathrm{Th}, \mathrm{K}$, and $\mathrm{Rb}$ content for dose rate calculations.

NOTE: As an example, assign the sample a consecutive laboratory number (e.g., BG4966) to label on each container that harbors any derivative of the original sample (e.g., BG4966<200 $\mu \mathrm{m}$ ). Link this BG number to the electronic laboratory log, co-registered with the sample field or submittal number. Include other information such as the core number, year collected, 
drive designation (e.g., B drive), and depth. Labeling subsamples in the lab is a critical task and should be done with exactitude to maintain the chain of sample custody.

4. Extract (10-30 g) the light-shielded sediment carefully with a spatula from the circular, scored central area of the core. Place the extract in a labeled $250 \mathrm{~mL}$ polyethylene beaker. Clean this sample physically and chemically to isolate a quartz fraction for luminescence dating.

NOTE: Perform core sampling in one direction (usually top to bottom) and one at a time to avoid sampling errors and contamination. Process the samples individually, in numerical order, to maintain the chain of custody.

5. Fill the remaining sample cavity in the core with a ball of aluminum foil to designate sample position and prevent sidewall collapse of the split core. Moisten the core face with DIW using a spray bottle, wrap in plastic, and seal the core for archiving.

\section{Extract mono-mineralogic quartz (Figure 6)}

NOTE: All personnel prior to initiating procedures in the lab are required to wear personal protective equipment (PPE), which includes a heavy and impermeable lab coat, accompanied by nitrile disposable gloves and goggles, and dust masks. This PPE is complemented with heavy PVC gloves and body-long apron, acrylic face shield, and reusable silicone waterproof shoe covers when using solvents at full strength for digestions.

1. Remove organic matter: Add slowly $30 \mathrm{~mL}$ of $25 \% \mathrm{H}_{2} \mathrm{O}_{2}$ to $30-60 \mathrm{~g}$ of the sediment in a $250 \mathrm{~mL}$ polyethylene beaker to remove organic matter. Stir well with a glass rod to facilitate the reaction. Add $\mathrm{H}_{2} \mathrm{O}_{2}$ until there is no visible effervescence with the release of $\mathrm{CO}_{2}$; let it sit inside the fume hood for at least $12 \mathrm{~h}$.

CAUTION: Perform this procedure under a fume hood. $\mathrm{H}_{2} \mathrm{O}_{2}$ promotes rapid oxidation, is corrosive, and can be very harmful to the eyes, skin, and respiratory system. A lab coat, chemical-resistant gloves, safety goggles, and a shield are required when handling reagent-grade $\mathrm{H}_{2} \mathrm{O}_{2}$. The addition of $\mathrm{H}_{2} \mathrm{O}_{2}$ to sediment containing organic matter is an exothermic reaction. The rapid increase in temperature is proportional to the abundance of organic matter disseminated in the sample. The addition of DIW may be necessary to keep reaction temperature $<40^{\circ} \mathrm{C}$. Continue to add $\mathrm{H}_{2} \mathrm{O}_{2}$ and monitor reaction temperature simultaneously. Let the mixture remain under a fume hood for $12 \mathrm{~h}$ covered by a wax sealant. Place the beaker in a $300 \mathrm{~mL}$ ceramic bowl filled with $100 \mathrm{~mL}$ of cold tap water to cool the reaction and capture reaction spillage. NOTE: If the organic matter content is $>3 \%$, the sample may require 1-3 days of soaking in $\mathrm{H}_{2} \mathrm{O}_{2}$ to react with organic carbon fully. Monitor the exothermic heat evolved and add DIW to keep it below $40{ }^{\circ} \mathrm{C}$. Do not heat the sample above $40{ }^{\circ} \mathrm{C}$. Higher temperatures may cause partial resetting of the luminescence signal and sensitivity changes detrimental to dosimetric measurements.

2. Wash the sample five times with $100 \mathrm{~mL}$ of DIW to remove any remaining $\mathrm{H}_{2} \mathrm{O}_{2}$ and halides present in the sediment. After settling for $30-60 \mathrm{~min}$, decant the supernatant into the sink with the water running. Take care to preserve the sediment at the beaker bottom during decanting.

3. Slowly add $30 \mathrm{~mL}$ of $15 \% \mathrm{HCl}$ for each $5 \mathrm{~g}$ of sediment in a $250 \mathrm{~mL}$ beaker to react with the $\mathrm{Ca} / \mathrm{MgCO}_{3}$ 
disseminated in the sample. Initially add $\leq 1 \mathrm{~mL}$ to assess effervescences and modulate further $\mathrm{HCl}$ additions to control better reaction. Stir well with a glass rod to facilitate the completion of the reaction. Add more $\mathrm{HCl}$ if necessary until there is no visible effervescence with the release of $\mathrm{CO}_{2}$.

CAUTION: Use $\mathrm{HCl}$ inside a fume hood, with the sash no more than a quarter open. A lab coat, chemical-resistant gloves, safety goggles, and a shield are required when handling this and other acids. The reaction of $\mathrm{HCl}$ with $\mathrm{Ca} / \mathrm{MgCO}_{3}$ is exothermic. The addition of DIW may be necessary to keep reaction temperature $<40{ }^{\circ} \mathrm{C}$. Continue to add $\mathrm{HCl}$ and simultaneously monitor reaction temperature. Let the mixture remain inside a fume hood for $8 \mathrm{~h}$ covered by wax paper. Place the beaker in a 300 $\mathrm{mL}$ ceramic bowl filled with $100 \mathrm{~mL}$ of cold tap water to cool the reaction and capture reaction spillage.

1. Wash the sample with $100 \mathrm{~mL}$ of DIW five times and decant carefully to remove excess (diluted) $\mathrm{HCl}$ into a sink with the water running.

2. Dry the sediment overnight in a box oven at $40{ }^{\circ} \mathrm{C}$.

4. Remove the magnetic, paramagnetic, and diamagnetic minerals.

NOTE: Most sediments contain $<10 \%$ magnetic minerals. Perform magnetic mineral removal of the sediment in a dry state using neodymium magnets or wet state using the dispersant Na-pyrophosphate $\left(\mathrm{Na}_{4} \mathrm{P}_{2} \mathrm{O}_{7} \cdot 10 \mathrm{H}_{2} \mathrm{O}\right)$ solution $(0.3 \%)$. Removal of magnetic and associated minerals is necessary as these components compete with HF etching of quartz and dissolution of other silicate minerals.
1. Wrap a $\sim 2.5 \mathrm{~cm}$ long neodymium magnet with a 38 $\mu \mathrm{m}$ nylon mesh sleeve for dry sediment removal of magnetic minerals.

2. Place the wrapped magnet on the outside wall of the beaker and move in a circular motion to attract magnetic minerals.

3. Move the magnet slowly to the top of the beaker to extract the minerals into a $20 \mathrm{~mL}$ ceramic dish. Remove the magnet and detach the magnetic minerals attached to the nylon sleeve.

4. Repeat steps 3.4.1-3.4.3 until to remove the magnetic grains completely; usually after 5 to 6 repeats.

5. To remove the magnetic grains in a water-based solution, place the sediment in a $250 \mathrm{~mL}$ glass beaker with $\sim 100 \mathrm{~mL}$ of $0.3 \%$ Na-pyrophosphate solution and stir thoroughly until the sediment is well disaggregated.

6. Place the beaker on a hot plate with a built-in magnetic stirrer; set stir rate at 800 RPM at ambient laboratory temperature. Submerge the magnetic rods and stir the sediment for $5 \mathrm{~min}$.

7. Remove the rods to clean off attracted magnetic grains by rubbing with a cloth or another magnet before returning the magnets to the solution. Repeat until no magnetic minerals are recovered; up to five repeats may be necessary.

NOTE: A binocular microscopic inspection of the sample is advised to assess the status of magnetic mineral removal. Together, the dry and wet magnetic mineral removal is usually $>95 \%$ effective.

5. Separate a specific grain-size fraction. 
NOTE: The particle size range of quartz grains to be separated is based on the previously determined particle size distribution for each sample (see step 1.1.5). Common particle size ranges to separate quartz grains are $500-450 \mu \mathrm{m}, 450-355 \mu \mathrm{m}$, and $355-250 \mu \mathrm{m}$ for medium sand, $250-150 \mu \mathrm{m}$ and $150-100 \mu \mathrm{m}$ for fine sand and $100-63 \mu \mathrm{m}$ for very fine sand.

1. Cut $15 \mathrm{~cm} \times 15 \mathrm{~cm}$ squares from rolls of nylon mesh of two sizes (e.g., $150 \mu \mathrm{m}$ and $250 \mu \mathrm{m}$ ) for particle size isolation using wet sieving with disposable meshes.

2. Frame the cut mesh in a $10 \mathrm{~cm}$-inner diameter circular plastic guide. For example, to target the fine sand fraction 150-250 $\mu \mathrm{m}$, use two framing meshes sequentially: $250 \mu \mathrm{m}$ first and $150 \mu \mathrm{m}$ second.

3. Label three beakers with the laboratory sample number (BGXXXX) and sieving limits; >150 >250 $\mu \mathrm{m}$, and 250-150 $\mu \mathrm{m}$ (Inset Figure 6A).

4. Place the circular sieving guide tightly with framed mesh, e.g., first, use $250 \mu \mathrm{m}$ (coarser grain size) over a 1-L beaker rim (10.5 cm diameter).

5. Sieve sample to the targeted particle size range, e.g., 250-150 $\mu \mathrm{m}$. Set up 1-L beaker with $250 \mu \mathrm{m}$ mesh guide on top; ready to sieve.

6. Add $\sim 100 \mathrm{~mL}$ of $0.3 \%$ solution of Na-pyrophosphate to a $250 \mathrm{~mL}$ beaker that contains the nonmagnetic sediment obtained in step 3.4.7 and stir thoroughly with a glass road to facilitate particle dispersion.

7. Continue to manually swirl the dispersed sediment mixture, and slowly pour through the $250 \mu \mathrm{m}$ mesh. The sediment of particles $<250 \mu \mathrm{m}$ size passes through the mesh into the below beaker and is the target for further size separation. Archive the sediment remaining on the mesh $(>250 \mu \mathrm{m})$ for possible future analysis.

8. Set up the $150 \mu \mathrm{m}$ mesh over a new dry 1-L beaker. Take the dispersed sediment mixture of step 3.5.7, continue to swirl in hand, and slowly pour through the $150 \mu \mathrm{m}$ mesh. The sediment of particles $<150 \mu \mathrm{m}$ size passes through the mesh into the below beaker. Archive the sediment for possible future analysis. The sediment remaining on the 150 mesh is the target size fraction, $150-250 \mu \mathrm{m}$, for OSL dating.

9. Dry the sediments in a box oven overnight at $40^{\circ} \mathrm{C}$.

6. Isolate quartz grains from the 250-150 $\mu \mathrm{m}$ size separately (Inset Figure 6B).

NOTE: This procedure includes two density separations using the non-toxic heavy liquid Sodium Polytungstate (SPT-Na6 $\left.\left(\mathrm{H}_{2} \mathrm{~W}_{12} \mathrm{O}_{40}\right){ }_{-} \mathrm{H}_{2} \mathrm{O}\right)$ at densities $2.6 \mathrm{~g} / \mathrm{cc}$ and $2.7 \mathrm{~g} / \mathrm{cc}$. Mix the powder with DIW to constitute this heavy liquid. To prepare $100 \mathrm{~mL}$ of the heavy liquid with a density of $2.6 \mathrm{~g} / \mathrm{cc}$, add $205.5 \mathrm{~g}$ of SPT to $54.5 \mathrm{~mL}$ of DIW. Whereas, to prepare $100 \mathrm{~mL}$ of the heavier liquid with a density of $2.7 \mathrm{~g} / \mathrm{cc}$, add $217.5 \mathrm{~g}$ of SPT to $52.7 \mathrm{~mL}$ of DIW. Assess the density of the heavy liquid with precalibrated density beads and a hydrometer.

CAUTION: Use only DIW to prepare heavy liquids because tap water contains dissolved ions that react and change the composition of the SPT powder. To generate a homogeneous solution of the desired density, add the SPT powder to the water and not the counter.

1. Label two $100 \mathrm{~mL}$ beakers with the sample number adding " $<2.6$ " to one beaker and ">2.6" to the other beaker. Keep a $1 \mathrm{~L}$ beaker ready to collect the heavy liquid washed from the sample with DIW. 
2. Mix thoroughly $80-70 \mathrm{~mL}$ of $2.6 \mathrm{~g} / \mathrm{cm}^{3}$ heavy liquid with the dry fraction of the sediment obtained in step 3.5.8. Pour the mixture into a well labeled $100 \mathrm{~mL}$ graduate cylinder. Cover the top with a wax sealant to avoid evaporation. Place the cylinder inside a fume hood to remain undisturbed and shielded from light. Wait for at least $1 \mathrm{~h}$ to allow the sample to separate in two markedly different zones. The higher floating, lighter minerals are often enriched in Kfeldspar and Na-rich plagioclases, and the lower heavier grains are rich in quartz and other heavier minerals.

NOTE: The separation times using the $2.6 \mathrm{~g} / \mathrm{cc}$ heavy liquid for smaller particle sizes, $<100 \mu \mathrm{m}$, may take $>4 \mathrm{~h}$.

3. Place a plastic funnel and place a disposable paper filter over a $250 \mathrm{~mL}$ beaker. Filter the solution with a tight fit.

4. Decant the floating sediment of the $2.6 \mathrm{~g} / \mathrm{cm}^{3}$ heavy liquid through the filter slowly and carefully, with suspended grains captured on the filter. Preserve the lower zone of settled grains carefully. Let the liquid pass through the filter; wash with DIW as needed.

5. Transfer the washed light sediment to the beaker labeled as "sample number <2.6", placing the paper filter in the beaker and washing carefully with DIW. Discard the filter after washing off all the grains.

6. Wash the sample five times with DIW to remove vestiges of heavy liquid.

7. Dry the sediments in the oven overnight at $<40^{\circ} \mathrm{C}$. Store this feldspar-rich fraction for future analyses.
8. Put a new filter paper on the plastic funnel and place it tightly on a $1 \mathrm{~L}$ glass beaker. Decant the lower settled mineral grains in the graduated cylinder with $2.6 \mathrm{~g} / \mathrm{cm}^{3}$ solution. Then, wash out the cylinder with DIW using a squirt bottle.

9. Transfer the washed "heavy" sediment to the beaker labeled with the "sample number $>2.6$ ". Place the paper filter in the beaker and wash carefully with DIW. Discard the filter after washing off all the grains.

10. Wash the sample three times in the sink with DIW.

11. Dry the sediments in the oven overnight at $<40^{\circ} \mathrm{C}$ for further density separation using $2.7 \mathrm{~g} / \mathrm{cc}$ heavy liquid.

12. Continue with quartz separation with a $2.7 \mathrm{~g} / \mathrm{cc}$ heavy liquid. Combine the dry "heavy" separate from the beaker labeled "sample number >2.6" with 70-80 $\mathrm{mL}$ of $2.7 \mathrm{~g} / \mathrm{cc}$ heavy liquid.

13. Decant the floating sediment (quartz-rich) onto a funnel-filter pair over a $1 \mathrm{~L}$ beaker slowly and carefully. Wash the floating sample on the filter thoroughly with DIW and collect the wash in the beaker below.

14. Transfer the washed sediment on the filter to a 250 $\mathrm{mL}$ polypropylene beaker labeled with the "sample number + for HF". Place the paper filter in the beaker and wash carefully with DIW; discard the filter after washing off all the grains.

15. Put a new paper filter on the plastic funnel, and place both on a new $1 \mathrm{~L}$ glass beaker. Add DIW to the cylinder where the $2.7 \mathrm{~g} / \mathrm{cc}$ density separation occurred, decant and wash with DIW until the lower separated grains are transferred completely to the 
filter. Repeat steps 3.6.10-3.6.12 and archive this heaviest fraction.

7. Etch the quartz grains by immersing in hydrofluoric acid NOTE: This procedure has two main goals: 1) to dissolve any remaining minerals other than quartz; 2 ) To etch the external $10-20 \mu \mathrm{m}$ of quartz grains, affected by the alpha radiation $^{28}$.

CAUTION: Concentrated hydrofluoric acid (HF) is a highly toxic and hazardous liquid. Special training and care are needed to use HF because of the high dermal and pulmonary toxicity. Lab personnel must be familiar with the HF Material Safety Data Sheets. Always handle $\mathrm{HF}$ inside an operational laboratory fume hood, near an eyewash and safety shower station. Never work with HF alone. Ensure that non-expired $2.5 \%$ calcium gluconate gel antidote is at hand before handling HF. The following PPE must be worn prior to handling HF: Long pants and sleeves, closed-toe shoes, heavy lab coat, acidresistant apron, thick nitrile gloves (10-20 mil), PVC or neoprene gloves that cover the hands, wrists, and forearms, dust mask, goggles, acrylic face shield, and silicone waterproof shoe covers.

1. Prepare a timer for $80 \mathrm{~min}$ and cut wax paper sealant to cover a $250 \mathrm{~mL}$ beaker.

2. Turn on both the DIW and regular water taps at the sink and have a bottle of DIW at hand as a safety precaution.

3. Put on the appropriate PPE to use HF acid.

4. Place a $250 \mathrm{~mL}$ heavy-duty polypropylene beaker with the sample obtained in step 3.6.14 inside the fume hood; lower the sash to near closure to be safe and comfortable to work. Add HF to the beaker by pump increments $(20 \mathrm{~mL})$ for every $2 \mathrm{~g}$ of quartz and cover the beaker with wax paper sealant.

NOTE: For enhanced safety, use an HF bottle dispenser that delivers set volumes of acid, e.g., 20 $\mathrm{mL} /$ pump, to control the amount and direction of acid delivery. High-density plastic containers are used with $\mathrm{HF}$ because this acid reacts with and etches glass.

5. Start the 80 min timer and remove the HF-PPE. Keep in mind to wear the PPE again to clean the sample $5 \mathrm{~min}$ before the time is complete.

6. Wash the sample five times under the hood. Fill the beaker with DIW to dilute the acid and decant it into a satellite container used for HF waste.

7. Remove the sample from the fume hood and wash the sample three more times with DIW at the sink, keeping both the DIW and regular water taps open to dilute any remaining HF further.

8. Decant and move the sample into a $250 \mathrm{~mL}$ glass beaker, add $150 \mathrm{~mL}$ of $0.3 \%$ Na-Pyrophosphate $\left(\mathrm{Na}_{4} \mathrm{P}_{2} \mathrm{O}_{7} \cdot 10 \mathrm{H}_{2} \mathrm{O}\right)$ solution to the sediment and place the beaker in a sonicator bath for $20 \mathrm{~min}$ to fully disaggregate the grains and particles.

9. Wash the sample five more times with DIW at a sink to remove the Na-pyrophosphate. Decant and label the beaker "Sample Name" for $\mathrm{HCl}$ ".

8. Immerse the mineral grains remaining after HF digestion (step 3.7.9) in concentrated $\mathrm{HCl}$.

CAUTION: Concentrated $\mathrm{HCl}(\sim 36 \%)$ is considered a toxic and corrosive fluid that can cause chemical burns upon contact and eye damage if splashed, and injury to the mouth, throat, esophagus, and stomach if ingested. Workers are required to be familiar with the $\mathrm{HCl}$ Material 
Safety Data Sheets. Always handle concentrated $\mathrm{HCl}$ inside an operational fume hood, near an eyewash and safety shower station. Never work with $\mathrm{HCl}$ alone. Before starting the digestion of the sediment with $\mathrm{HCl}$, be sure to wear the PPE listed in step 3.7.

NOTE: As with concentrated HF, it is safer to use a bottle dispenser to control the amount and direction of the discharge. Use glass containers when working with $\mathrm{HCl}$. Before removing the PPE, wash the gloves with soap and water, and after removing the PPE, wash hands and forearms.

1. Prepare the wax sealant to cover the beaker with the sample immersed in the acid.

2. Turn on both the DIW and regular water taps at the sink and have a bottle of DIW at hand as a safety precaution.

3. Put on the acid PPE.

4. Place the $250 \mathrm{~mL}$ glass beaker with the sample obtained in step 3.7.9 inside the fume hood. Lower the sash to near closure to be safe and comfortable to work. Add $\mathrm{HCl}$ to sample by pump increments ( 20 $\mathrm{mL}$ ) for every $5 \mathrm{~g}$ of quartz and then cover the beaker with wax sealant paper.

5. Remove the acid PPE.

6. Leave the sample for $\mathrm{HCl}$ digestion for $8 \mathrm{~h}$ in the fume hood.

7. Put on the acid-PPE before cleaning the $\mathrm{HCl}$.

8. Wash the sample five times under the hood; decant supernatant into the satellite container to collect $\mathrm{HCl}$ waste.

9. Wash the sample three more times with DIW at the sink, keeping both the DIW and regular water taps open for further dilution. Make sure to continue wearing the necessary PPE.

9. Re-sieve the sediments through the smallest prior mesh (e.g., $150 \mu \mathrm{m}$ ) to remove fractured and broken grains.

10. Decant and label the beaker "Sample Name for OSL" and dry the sediments in the oven for at least $8 \mathrm{~h}$ at $<40^{\circ} \mathrm{C}$ to evaluate the purity of quartz separation of this finished product.

11. Quantify quartz separate purity

1. Use a dissecting needle to place $200-400$ mineral grains on a glass slide and inspect under a 10x or 20x binocular and/or petroscopic microscope to identify grain minerals. Quantify the percentage of quartz grains by point counting and record the mineralogy of 100 individual grains. If a subsample exhibits $>1 \%$ non-quartz minerals and is an unwanted mineral with high photon output (e.g., K-feldspar) or remains unidentified, cue the sample for Raman spectroscopy.

2. Use Raman spectroscopy and associated image to confirm the grain mineralogy and identify minerals unrecognized under microscopic inspection. Use a blue beam with a width of $5 \mu \mathrm{m}$ and 100-grain point counts to assess the percent purity of quartz and identify the unknown grain minerals.

12. Assess the quartz purity spectra by infrared stimulation

1. Prepare five ultra-small aliquots of quartz separates for IR stimulation by shaking grains onto a circular aluminum disc (1 $\mathrm{cm}$ diameter). Each aliquot usually contains approximately 20-100 quartz grains corresponding to a $1 \mathrm{~mm}$ or less circular diameter adhered (with silicon) to a disc. 
2. Load the discs on a sample carousel for stimulation by IR LEDs ( $845 \mathrm{~nm} \pm 4 \mathrm{~nm}$ ) delivered by an automated TL/OSL reader system and compare it with the blue light excitation $(470 \mathrm{~nm} \pm 20 \mathrm{~nm})$, which is preferential for quartz.

3. Ensure that the ratio between IRSL and blue light emissions of quartz grain aliquots is $<5 \%$. If such is the case, the sample is ready for further analysis. Otherwise, the sample requires additional cleaning with HF (step 3.7).

\section{Representative Results}

The laboratory procedures outlined are focused on enhancing the separation of pure quartz grains (700 to $50 \mu \mathrm{m}$ size) needed for OSL dating without inadvertent light resetting in the laboratory (Figure 1). A pure quartz separate, mineralogically and optically, is a prerequisite for applying SAR and TT-OSL dating procedures (Figure 2). These procedures explain the necessary steps for effectively understanding and sampling continuous sediment cores, avoiding zones of pedogenesis and diagenesis, retrieving unlight-exposed sediments from cores (Figure 3 and Figure 4); to isolate quartz grains for OSL dating protocols to constrain the timing of sediment deposition in the past ca. 500 ka (Figure 5). The mineralogy of grains of the unprepared sample and prepared separates are assessed continuously through the preparation process to identify the contaminating mineralogy and actively assess the process of removal of unwanted minerals (Figure 6 and Figure 7).
The quartz mineralogic purity is determined for subset grains (100-400) through binocular microscopic inspection (10-20x) and by Raman spectroscopy. The use of this technology and prerequisite knowledge is vital to assess and confirm the needed purity (>99\%) of quartz separations for OSL dating (Figure 8).

The process for quartz separation is started with the removal of organic matter with $\mathrm{H}_{2} \mathrm{O}_{2}$ and then the subsequent purging of $\mathrm{Ca} / \mathrm{MgCO}_{3}$ with soaking in $\mathrm{HCl}$. Subsequently, a size fraction is designated by sieving with disposable nylon mesh (e.g., 150 and $250 \mu \mathrm{m}$ ), which is necessary for calculating dose rate values (in $\mathrm{mGy} / \mathrm{y}$ ) (Figure 6A inset). The purity of the quartz separate is enhanced by two density separations at 2.6 and $2.7 \mathrm{~g} / \mathrm{cc}$, the bounding density of quartz (Figure 6B inset). The subsequent soaking of sized grains in HF for 80 min removes non-quartz minerals. This treatment also etches the outer $10-20 \mu \mathrm{m}$ of grains to remove the alphadose affected area, simplifying dose rate calculations (Figure 6). The purity of the quartz separate is never assumed but assessed through binocular microscopic inspection and Raman-based measurements at the end of grain separation. Density separations and/or HF treatment can be repeated to rid the separate contaminating grains if a representative aliquot contains $>1 \%$ non-quartz grains, particularly feldspar minerals (Figure 7). The quartz purification procedure was repeated up to four times with quartz contents of $<15 \%$ to render shine down curves with a fast ratio of $>20$, characteristic of pure quartz (Figure 8). 


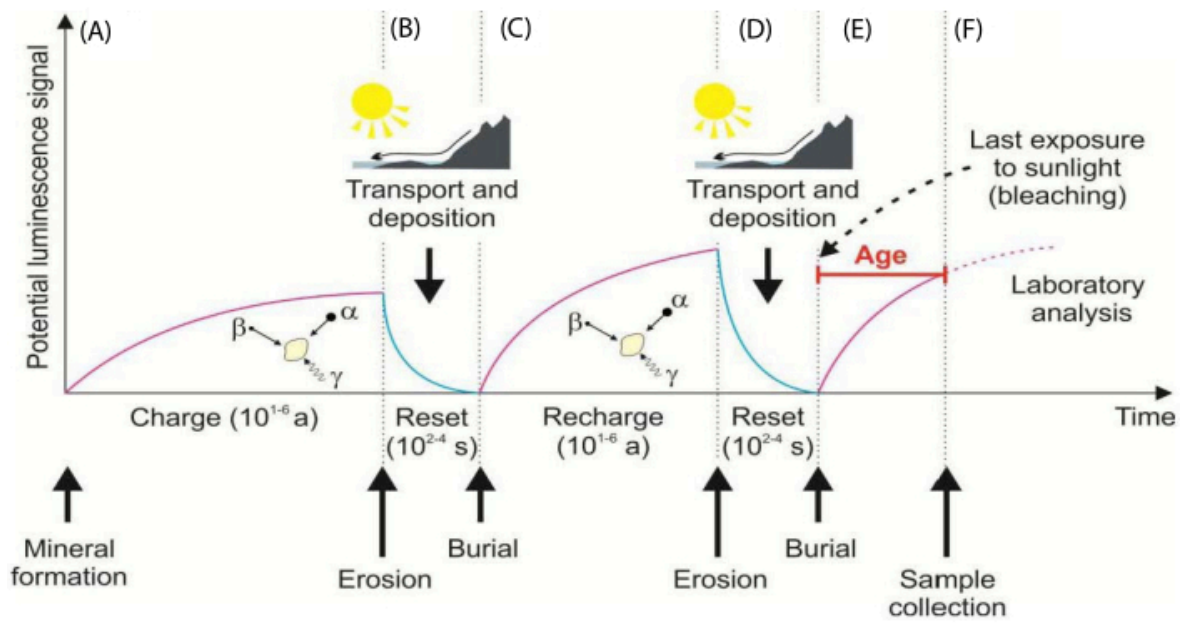

Figure 1: Processes with OSL dating. (A) Mineral grains acquire OSL with ionizing radiation exposure. (B) Grain OSL is reset by sunlight with erosion/ transport. (C) Exposure to ionizing with burial; luminescence acquired. (D) Light exposure resets OSL with erosion/ transport. (E) Grains are re-buried, and OSL is acquired with exposure to ionizing radiation. (F) Shows sampling without light exposure. The resultant measured natural OSL is followed by a normalizing test dose ( $L_{n} /$ $\left.T_{n}\right)$ which is equated to the regenerative dose curve to yield an equivalent dose $\left(D_{e}\right)$. This figure has been modified from Forman, S. L. et al. ${ }^{7}$. Please click here to view a larger version of this figure. 


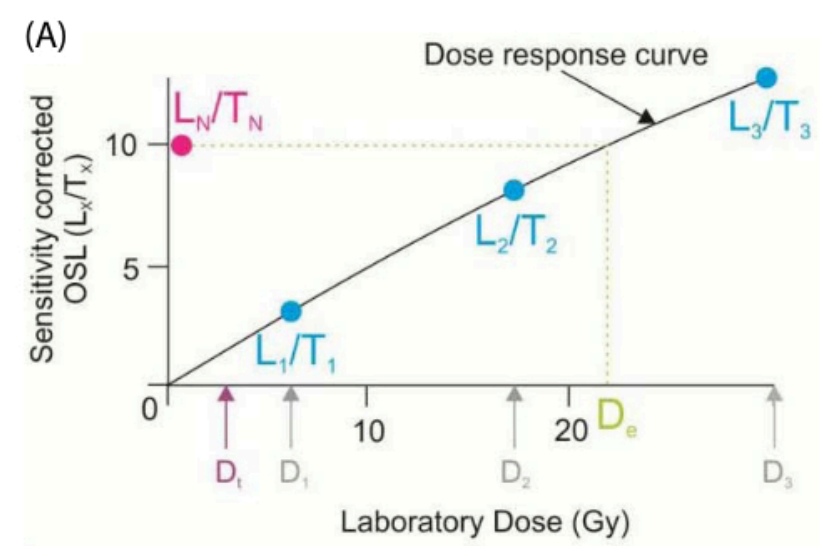

(B)

Step 1: Follow steps 2-8 to measure $L_{N}$ giving a dose $\left(D_{N}\right)$ of zero

\begin{tabular}{|c|}
\hline Step 2: Give dose, e.g. $\mathrm{D}_{1}$ \\
\hline Step 3: Preheat (usually $160{ }^{\circ} \mathrm{C}-280^{\circ} \mathrm{C}$ for $10 \mathrm{~s}$ ) \\
Step 4: Stimulate luminescence at $125^{\circ} \mathrm{C}$ for $40 \mathrm{~s}$ \\
Measure $\mathrm{L}_{1}$ \\
Step 5: Give test dose, e.g. $\mathrm{D}_{1}$ \\
Step 6: Heat ( $160{ }^{\circ} \mathrm{C}-280^{\circ} \mathrm{C}$ ) \\
\hline Step 7: Stimulate luminescence at $125^{\circ} \mathrm{C}$ for $40 \mathrm{~s}$ \\
Measure $\mathrm{T}_{1}$ \\
Step 8: Return to step 2 for proceeding doses (i.e. $\mathrm{D}_{2}, \mathrm{D}_{3}$ )
\end{tabular}

Figure 2: Optical Stimulating Luminescence- Single Aliquot Regeneration (OSL-SAR) protocols for quartz grains. (A) Equivalent dose using SAR protocols; the natural OSL is $L_{n} / T_{n}$, and the regenerative dose is $L_{X} / T_{\chi}$; sensitivity changes are corrected by giving a test dose (e.g., 5 Gy). (B) Generalized SAR protocol. This figure has been modified from Forman, S. L. et al. ${ }^{7}$. Please click here to view a larger version of this figure. 


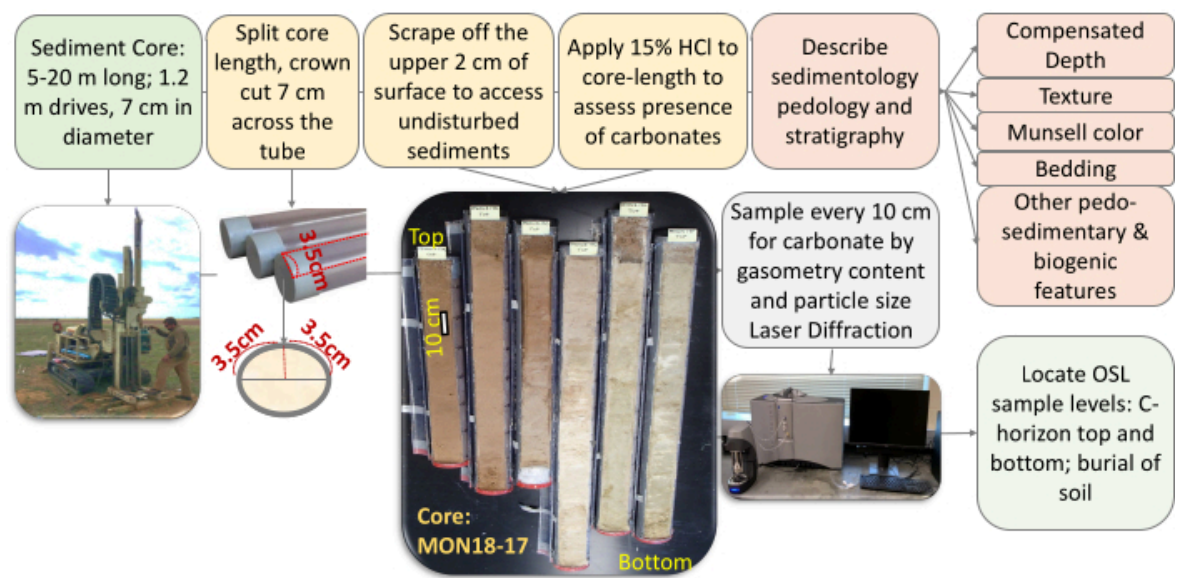

Figure 3: Flow diagram outlining the steps necessary to open, describe, and interpret a recovered sediment core.

This figure shows retrieval of sediment core using percussion corer, followed by the opening, cleaning, description, and study of the core to obtain the optimal sample for OSL dating. Please click here to view a larger version of this figure. 

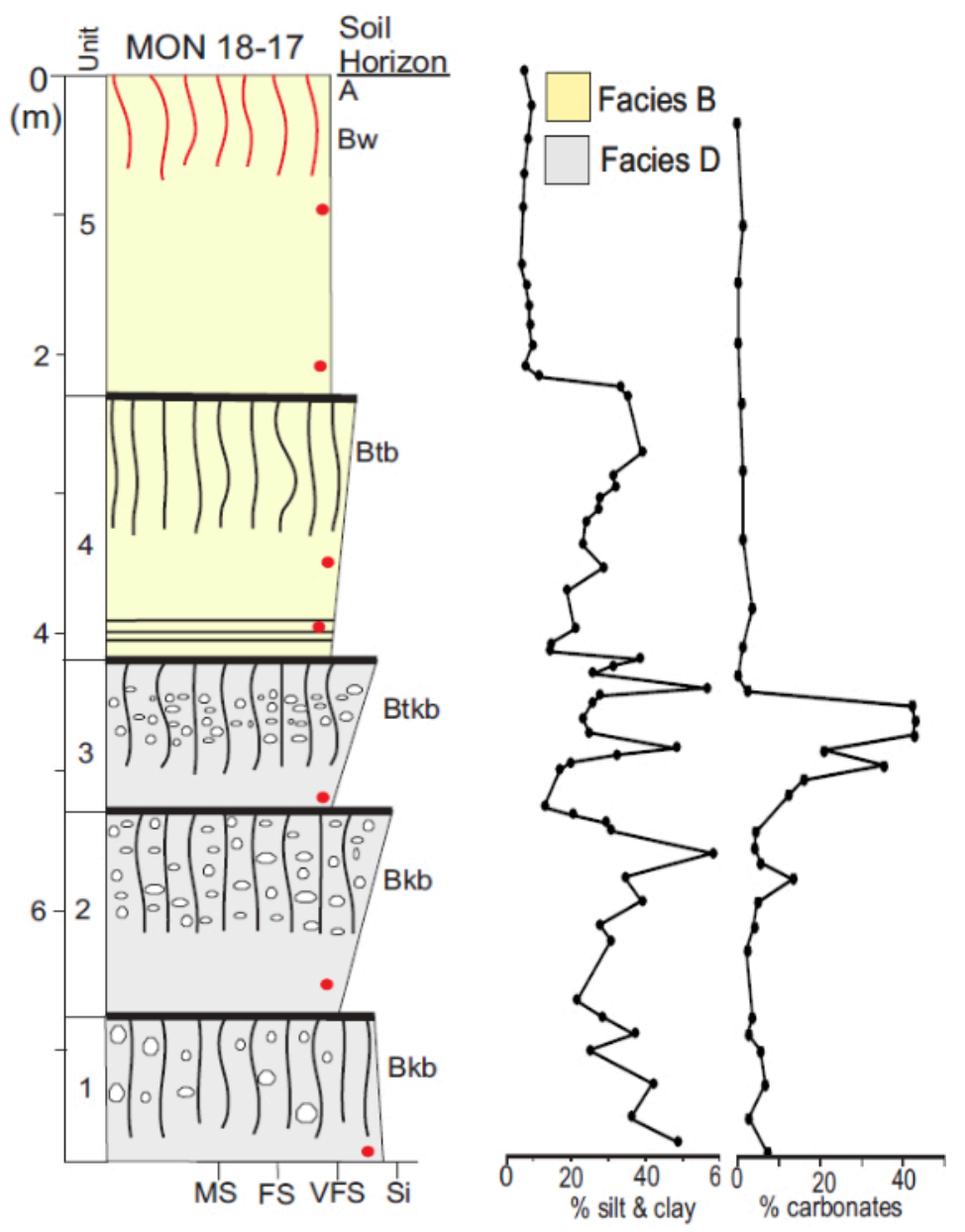

Figure 4: Example of a typical log of a core sedimentary and stratigraphic section. Units and pedosedimentary facies are defined using sedimentology, stratigraphy, pedology, granulometry, and carbonate percentage. The soils horizons found in the stratigraphic column from top to bottom are: A: Surface organic-rich horizon, B: subsoil with weak structure and color $(\mathrm{Bw})$, and buried B horizon Btb with clay accumulation, Btkb with secondary calcium carbonate and clay accumulation, and Bkb with an accumulation of secondary calcium carbonate. The dominant particle size of sedimentary units is shown on the lower horizontal with medium sand (MS), fine sand (FS), very fine sand (VFS), and Silt (Si). Please click here to view a larger version of this figure. 


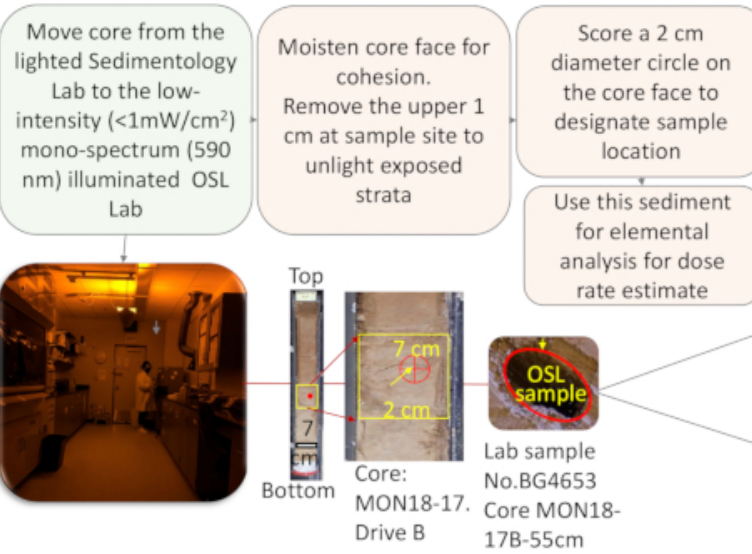

Extract light shielded sediment from the core. This sediment will be cleaned physically and chemically to isolate quartz grains for equivalent dose estimate.

Fill sample cavity with aluminum foil to prevent side wall collapse. Moisten, wrap in plastic, and seal the core for archiving

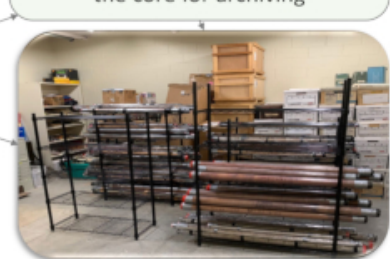

Figure 5: Flow diagram for the steps necessary to collect an OSL sample from a sediment core. This figure presents a flow diagram with the main steps followed to prepare a quartz separate for OSL dating. The protocols start with the extraction of a polymineral sediment from light-shielded areas of the core in the light safe OLS lab. They continue with the extraction of the mono-mineralogic fraction of quartz, comprising the removal of organic matter with peroxide, carbonates with $\mathrm{HCl}$, and magnetic minerals using hand magnets. The separation of the specific fraction of sand-size sediment is done by sieving; separation of minerals less dense and heavier than quartz is done using density liquids ( $\rho=2.6 \mathrm{~g} / \mathrm{cc}$ and $2.7 \mathrm{~g} / \mathrm{cc}$ ). The final steps of cleaning require immersion of the sediment into $\mathrm{HF}$ and $\mathrm{HCl}$ full strength to isolate quartz from any other mineral in the fraction. The purity of the separate is evaluated by binocular inspection, RAMAN spectroscopy, and further verification of IRSL (Infrared) emissions. The goal is to obtain a sample with a purity $\geq 99 \%$. Failure to do so requires that some of the steps must be repeated.Please click here to view a larger version of this figure. 


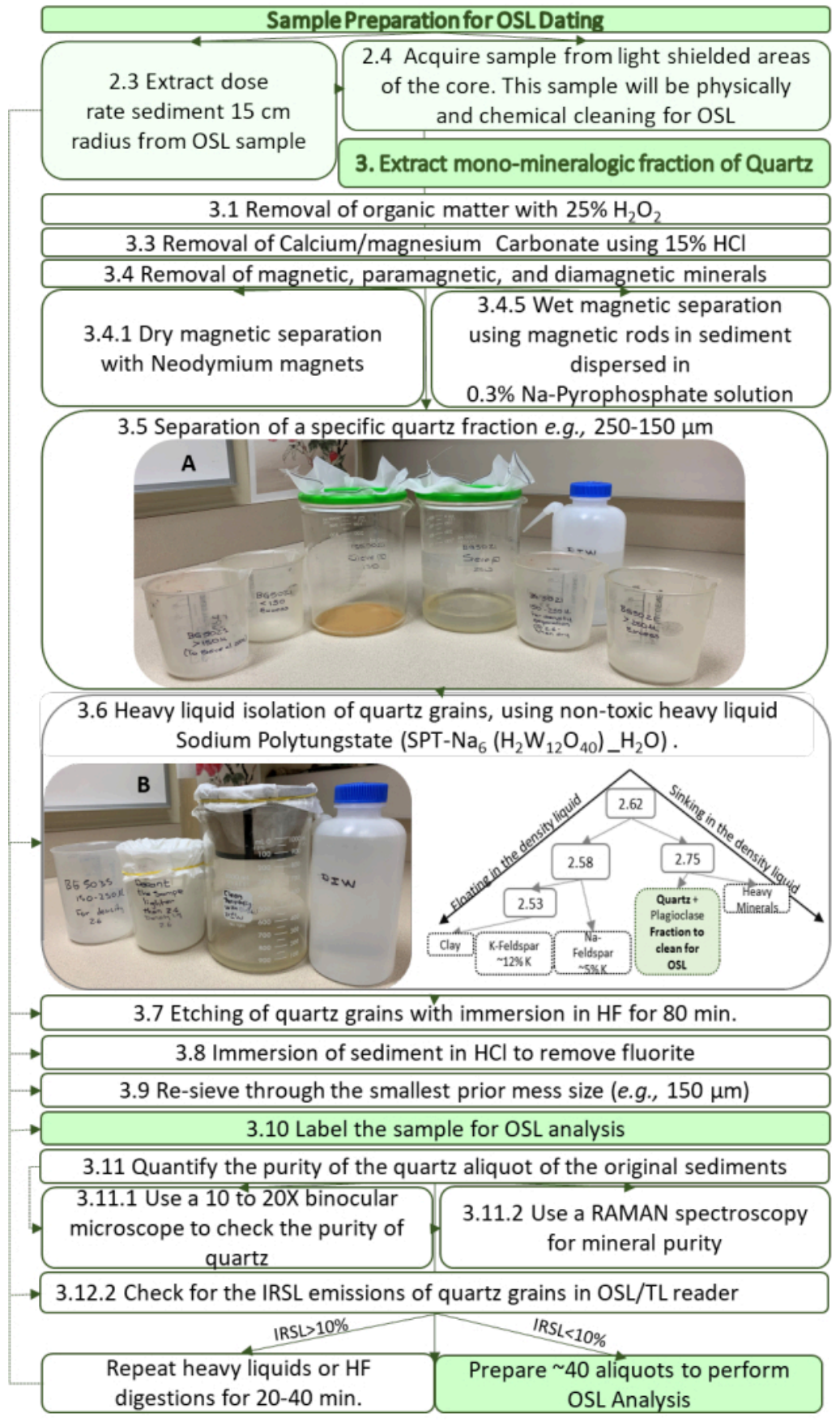

Figure 6: Flow chart depicting all the steps necessary to obtain a pristine quartz separate from a sediment sample from a core. This clean quartz fraction will be used for OSL-SAR analyses for age assessment. Please click here to view a larger version of this figure. 

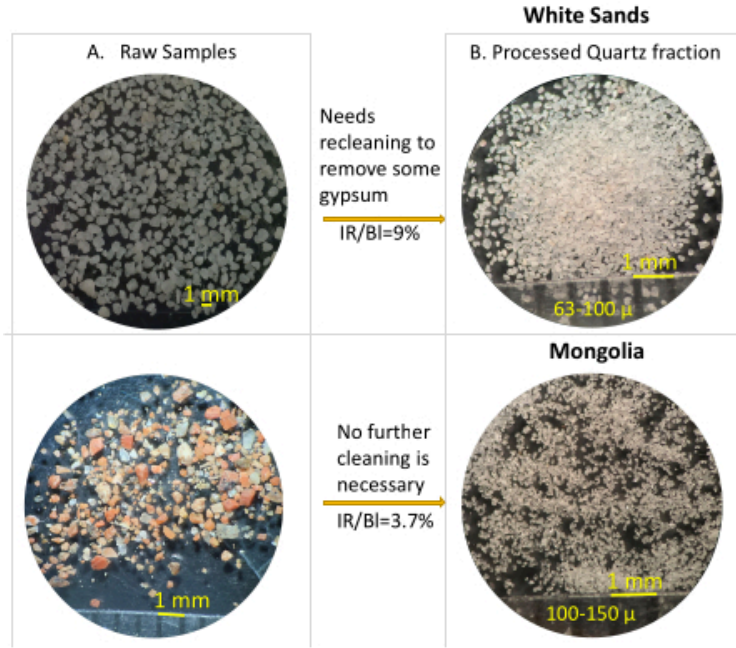

C. Raman Spectroscopy Results

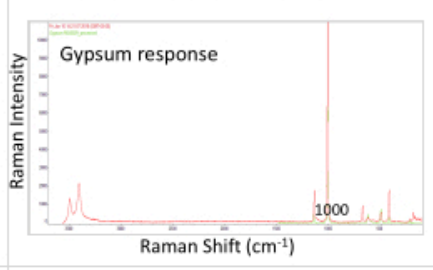

Raman Shift $\left(\mathrm{cm}^{-1}\right)$

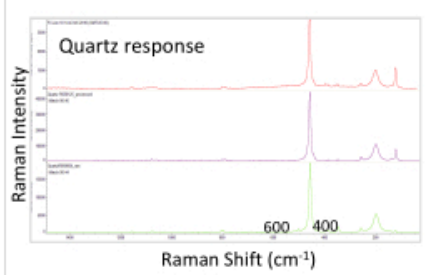

Figure 7: Comparison of two samples collected in two different areas: White Sands (first row) and Mongolia (second row). Column A shows raw samples under the binocular microscope, as collected in the field. Column B shows the separate fractions for each processed samples, under the binocular microscope. Column $\mathbf{C}$ shows the corresponding RAMAN spectroscopy results. The sample from White Sands contains sulfates (mainly gypsum), halides, and very little quartz (column A). Correspondently, the separate fraction $(63-100 \mu \mathrm{m})$ for the processed sample in a Column B shows that it contains mostly quartz, still with some vestiges of gypsum, as shown by the RAMAN Spectroscopy in Column $\mathbf{C}$. The ratio between the OSL IR and blue responses for this sample is $9 \%$, confirming that it needs a second separation in density at $2.6 \mathrm{~g} / \mathrm{cc}$, which possibly will remove the lighter gypsum $(2.36 \mathrm{~g} / \mathrm{cc})$ from heavier quartz. Contrastingly, the Mongolian sample (Column A) is initially very rich in feldspars, predominantly K-feldspar. After undergoing the cleaning procedures, shows abundant quartz isolated in the 100-150 $\mu \mathrm{m}$ separate (Columns B and C), rendering a satisfactory IR/BI ratio of $3.7 \%$. Please click here to view a larger version of this figure. 


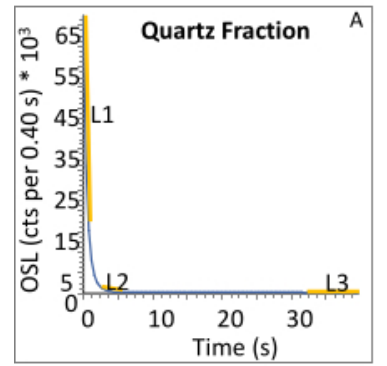

RR-18-OK D. 17: BG501X 250-150 Fast Component: 72

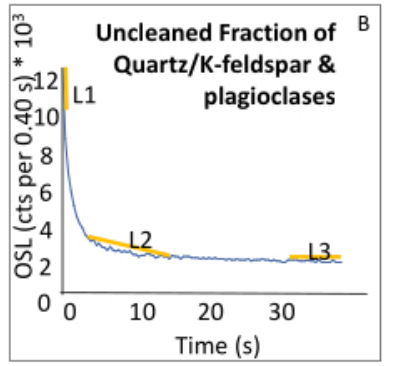

Asia-20 D.18: BG492X 150-250 Fast Component: 6.13

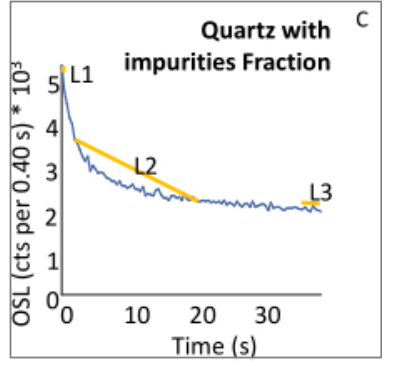

WA-20 D. 18: BG494X 250-150 Fast Component: 2.67

Figure 8: Comparison of fast ratio for the natural in three samples that represent different degrees of quartz fraction purity. (A) The ideal fast ratio distribution in a pristine eolian sample from Red River, with fast ratio $=72$. Contrasting figures (Figure 8B,C) have a less fast component with blue LED stimulation, which is below 20. (B) A sample with incomplete quartz and plagioclases separation. The L2 and L3 components are a significant \% of the L1 component (see Equation 2). (C) A shine-down curve for feldspathic quartz, with a dominant medium component (L2). Please click here to view a larger version of this figure.

\section{Discussion}

Quartz mineralogical purity is critical for OSL dating. However, quartz spectral purity is equally important and is usually enhanced with the careful concentration of quartz grains. Ideally, quartz grains under blue LED light (470 $\mathrm{nm} \pm 20 \mathrm{~nm}$ ) stimulation for $40 \mathrm{~s}$ should emit $\geq 90 \%$ of the luminescence within the first $\sim 0-2.5 \mathrm{~s}$ of stimulation, termed the fast component, with $<10 \%$ of light emission between $\sim 2.5$ and $\sim 15 \mathrm{~s}$ (medium component), and a final low emission post $\sim 15 \mathrm{~s}$, (slow component) (Figure 8). A luminescence emission dominated by a fast component is preferred because it is rapidly solar reset (in seconds) and shows high sensitivity to applied $\beta$ radiation in the laboratory, enhancing equivalent dose determinations. An important metric to assess the dominance of fast components for OSL dating of quartz is the calculation of a "fast ratio"29,30 with an example shown by Equation 2 and in Figure 8. A fast ratio of $>20$ for quartz shine down curve is considered a robust luminescence emission suitable for OSL dating ${ }^{29}$ (see Figure 8A). Separates that have contamination with $\mathrm{K}$-feldspars and plagioclase or feldspathic inclusions often yield fast ratios of $<10$ (see Figure 8B,C) and are unsuitable for SAR quartz dating protocols.

Fast Ratio $=\frac{L 1-L 3}{L 2-L 3}$ (Equation 2)

Where L1: Fast component emission for $\sim 0-2.5 \mathrm{~s}$

L2: Medium component emission $22.5-15$ s L3: Slow component emission $\sim 15-40 \mathrm{~s}$

An important test on the spectral purity of isolated quartz grains is the response of aliquots to infrared excitation from LEDs (845 nm $\pm 4 \mathrm{~nm}$ ). Most quartz grains yield a low or negligible luminescence emission with IR stimulation at or within a few hundred counts of background emissions. A metric has been developed to assess IR-based emissions, 
called the IR depletion ratio, which is calculated as a SAR ratio $\left(L_{X} / T_{X}\right)$ for irradiated (5-10 Gy) quartz grains stimulated with IR LEDs and then blue LEDs. Specifically, the ratio of IR luminescence divided by blue emissions should be $<5 \%$, which indicates a spectrally pure quartz fraction amenable for OSL dating (Figure 8A). However, there are instances that mineralogically pure quartz grains can yield errant luminescence emissions with IR stimulation. This IR signal may reflect adhering lithic fragments or feldspathic inclusions in quartz. In such instances, quartz grains should be dated by feldspar protocols ${ }^{31}$. These protocols with modifications can be used to separate and confirm the purity of other minerals for OSL dating, such as k-feldspar, plagioclase, and olivine and pyroxene for other planetary applications.

The ability to isolate a $>99 \%$ quartz separate and confirm the purity at the grain level is a prerequisite for accurate luminescence dating. Single-grain and ultra-small aliquot (10-50 grains) dating requires additional verification that the luminescence emissions of all grains were from quartz. In turn, the application of thermal transfer approaches that can yield credible OSL ages up to one million years is predicated on pure quartz signals from mineral grains ${ }^{6}$. A monomineralogic quartz separate is foundational for applying OSLSAR protocols, which provides a sequence of ages for deciphering the depositional history of eolian and fluvial systems for the late Quaternary 1,2,32,33 (Figure 1 and Figure 2). Contamination of quartz aliquots by the errant Kfeldspar grains or feldspathic inclusions in quartz or adhering lithic fragment yields a mixed dosimetric signal and prone to anomalous fading often yields underestimates ${ }^{4}$. However, a pure quartz separate does not absolutely ensure spectral purity and appropriate emissions for quartz dating. Effective OSL dating requires careful and complete isolation of quartz grains and OSL associated metrics to verify a pure quartz separate mineralogically and spectrally $2,33,34$.

\section{Disclosures}

The Baylor University Geoluminescence Dating Research Laboratory, within the Dept. of Geosciences and the associated personal do not have any conflicts of interest or financial interest that can affect the design of experiments or analysis, protocols, outcomes of the research or educational activities conducted in the lab. This Lab, including all the technology within and software, is used solely to conduct research, discovery, education, and mentoring.

\section{Acknowledgments}

Support of the Geoluminescence Dating Research Laboratory has been provided by Baylor University and grants from the National Science Foundation (GSS-166023), National Geographic (\#9990-1), and Atlas Sand. Discovery and learning in this lab were enhanced by our many collaborators, students, and visitors that have brought new perspectives, ideas, and approaches.

\section{References}

1. Murray, A. S., Wintle, A. G. The single aliquot regenerative dose protocol: Potential for improvements in reliability. Radiation Measurements. 37 (4-5), 377-381 (2003).

2. Wintle, A. G., Murray, A. S. A review of quartz optically stimulated luminescence characteristics and their relevance in single-aliquot regeneration dating protocols. Radiation Measurements. 41, 369-391 (2006).

3. Duller, GAT. RISO Luminescence Analyst. Version 4.57. Build:11/28/2018 at https://users.aber.ac.uk/ggd/, (2021). 
4. Aitken, M. J. An introduction to optical dating: the dating of Quaternary sediments by the use of photonstimulated luminescence. Oxford University Press, New York, (1998).

5. Duller, G. A. T., Wintle, A. G. A review of the thermally transferred optically stimulated luminescence signal from quartz for dating sediments. Quaternary Geochronology. 7 (1), 6-20 (2012).

6. Brown, N. D., Forman, S. L. Evaluating a SAR TTOSL protocol for dating fine-grained quartz within Late Pleistocene loess deposits in the Missouri and Mississippi river valleys, United States. Quaternary. Geochronology. 12, 87-97 (2012).

7. Forman, S., Luminescence Dating in Paleoseismology. Encyclopedia of Earthquake Engineering., 1371-1378, Springer Berlin Heidelberg (2015).

8. Lepper, K. and McKeever, S. W. S. An objective methodology for dose distribution analysis. Radiation Protection Dosimetry. 101 (1-4), 349-352 (2002).

9. Tsukamoto, S., Duller, G. A. T., Wintle, A. G., Muhs, D. Assessing the potential for luminescence dating of basalts. Quaternary Geochronology. 6, 61-70 (2011).

10. Li, S. H., and Chen, G. Studies of thermal stability of trapped charges associated with OSL from quartz. Journal of Physics D-Applied Physics. 34, (4), 493-498 (2001).

11. Fu, X., Li, S. H., and Li, B. Optical dating of aeolian and fluvial sediments in north Tian Shan range, China: Luminescence characteristics and methodological aspects. Quaternary Geochronology. 30, 161-167 (2015).
12. Hu, G., Li., S. -H. Simplified procedures for optical dating of young sediments using quartz. Quaternary Geochronology. 49, 31-38 (2019).

13. Porat, N. Use of magnetic separation for purifying quartz for luminescence dating. Ancient TL. 24 (2), 33-36 (2006).

14. Mejdahl, V. Thermoluminescence dating of sediments. Radiation Protection Dosimetry. 17, 219-227 (1986).

15. Fain, J., Soumana, S., Montret, M., Miallier, D., Pilleyre, T., Sanzelle, S. Luminescence and ESR dating-Betadose attenuation for various grain shapes calculated by a Monte-Carlo method. Quaternary Science Reviews. 18, 231-234 (1999)

16. Prescott, J. R., Hutton, J. T. Cosmic ray contributions to dose rates for luminescence and ESR dating: large depths and long-term time variations. Radiation Measurements. 23, 497-500 (1994).

17. Liang, P., Forman, S. L. LDAC: An excel-based program for luminescence equivalent dose and burial age calculations. Ancient TL. 37 (2), 21-40 (2019).

18. Lafuente, B., Downs, R. T., Yang, H., Stone, N. The power of databases: the RRUFF project.Highlights in Mineralogical Crystallography. Berlin, Germany, Boston: De Gruyter (O), 1-30 (2015).

19. Wintle, A G. Luminescence dating: laboratory procedures and protocols. Radiation Measurements. 27, 769-817 (1997)

20. Aitken, M. J. Thermoluminescence Dating. Academic Press, London, UK (1985).

21. Porat, N. Faerstein, G., Medialdea, A., Murray, A. S. Re-examination of common extraction and purification 
methods of quartz and feldspar for luminescence dating.

Ancient TL., 33 (1), 22-30 (2015).

22. Andò, S. Gravimetric Separation of Heavy Minerals in Sediments and Rocks. Minerals. 15p. (2020).

23. Nelson, M., Rittenour, T., Cornachione, H. Sampling methods for luminescence dating of subsurface deposits from cores. Methods and Protocols. 2, 88, 1-15 (2019).

24. Munsell Color. Munsell Soil Color Charts: with Genuine Munsell Color Chips. Grand Rapids, MI, Munsell Color (2010).

25. USDA Natural Resources Conservation Service Soils. Keys to soil taxonomy. Washington, DC, United States Department of Agriculture, Natural Resources Conservation Service. 20, (2014).

26. Malvern Instruments Ltd User Manual. at https://www.malvernpanalytical.com/en/products/ product-range/mastersizer-range/mastersizer-3000 (2013).

27. Wentworth, C. K. A scale of grade and class terms for clastic sediments. Journal of Geology. 30 (5), 377-392 (1922).

28. Mejdahl, V., Christiansen, H. H. Procedures used for luminescence dating of sediments. Boreas. 13, 403-406 (1994).

29. Madsen, A. T., Duller, G. A. T., Donnelly, J. P., Roberts, H. M., Wintle A. G. A. Chronology of hurricane landfalls at Little Sippewisset Marsh, Massachusetts, USA, using optical dating. Geomorphology. 109, 36-45 (2009).

30. Durcan, J. A., Duller, G. A. T. The fast ratio: A rapid measure for testing the dominance of the fast component in the initial OSL signal from quartz. Radiation Measurements. 46, 1065-1072 (2011).
31. Wang, Y., Chen, T., Chongyi, E., An, F., Lai, Z., Zhao, L., Liu, X. -J. Quartz OSL and K-feldspar post-IR IRSL dating of loess in the Huangshui river valley, northeastern Tibetan plateau. Aeolian Research. 33, 23-32 (2018).

32. Murray, A., Olley, J. Precision and accuracy in the optically stimulated luminescence dating of sedimentary quartz: A status review. Geochronometria. 21, 1-16 (2002).

33. Murray, A. S., Wintle, A. G. Luminescence dating of quartz using an improved single-aliquot regenerativedose protocol: Radiation Measurements. 32 (1), 57-73 (2000).

34. Timar-Gabor, A., Wintle, A. G. On natural and laboratory generated dose response curves for quartz of different grain sizes from Romanian loess. Quintenary Geochronology. 18, 34-40 (2013). 